\title{
Morphology and Electrical Conductivity of Carbon Nanocoatings Prepared from Pyrolysed Polymers
}

\author{
Marcin Molenda, Michał Świętosławski, Marek Drozdek, Barbara Dudek, \\ and Roman Dziembaj
}

Faculty of Chemistry, Jagiellonian University, Ingardena 3 Street, 30-060 Krakow, Poland

Correspondence should be addressed to Marcin Molenda; molendam@chemia.uj.edu.pl

Received 1 December 2013; Revised 13 March 2014; Accepted 14 March 2014; Published 13 April 2014

Academic Editor: Yu-Lun Chueh

Copyright (C) 2014 Marcin Molenda et al. This is an open access article distributed under the Creative Commons Attribution License, which permits unrestricted use, distribution, and reproduction in any medium, provided the original work is properly cited.

\begin{abstract}
Conductive carbon nanocoatings (conductive carbon layers-CCL) were formed on $\alpha-\mathrm{Al}_{2} \mathrm{O}_{3}$ model support using three different polymer precursors and deposition methods. This was done in an effort to improve electrical conductivity of the material through creating the appropriate morphology of the carbon layers. The best electrical properties were obtained with use of a precursor that consisted of poly-N-vinylformamide modified with pyromellitic acid (PMA). We demonstrate that these properties originate from a specific morphology of this layer that showed nanopores (3-4 nm) capable of assuring easy pathways for ion transport in real electrode materials. The proposed, water mediated, method of carbon coating of powdered supports combines coating from solution and solid phase and is easy to scale up process. The optimal polymer carbon precursor composition was used to prepare conductive carbon nanocoatings on $\mathrm{LiFePO}_{4}$ cathode material. Charge-discharge tests clearly show that $\mathrm{C} / \mathrm{LiFePO}$ composites obtained using poly-N-vinylformamide modified with pyromellitic acid exhibit higher rechargeable capacity and longer working time in a battery cell than standard carbon/lithium iron phosphate composites.
\end{abstract}

\section{Introduction}

There are many reports on the improvement of electrochemical performance of electrode materials for lithiumion batteries using carbon coatings [1-9]. The compounds reported for the coating formation include carboxylic acids [2], polyalcohols [3], resins $[4,5]$, and sugars [6]. To form the carbon coatings, the compounds were deposited on the electrode material grains and pyrolysed. However, morphology of these layers was not discussed in detail. Characteristic of carbon coatings deposited on electrodes is that they can react with the electrolyte thereby giving rise to the formation of passive insulating layers. To avoid these destructive effects, the carbon conductive layers should stick well to the electrode material and be able to reduce an interface area of the electrode/electrolyte composite. This reduction is needed to retard the growth of the solid electrolyte interface (SEI) that is responsible for the magnitude of the ion transport across the interface. In view of the above, the formation of nanochannels (the appropriate porous structure) in the conductive carbon layers (CCL) can provide suitable pathways for the transport of ions (e.g., $\mathrm{Li}^{+}$) from the electrolyte to the cathode and vice versa. Such a composite material should assure also a sufficient electrical conductivity.

The aim of the present work was to study the influence of different polymer precursors, methods of their deposition and transformation into CCL on the morphology, electrical properties, and the performance of formed layers on the surface of $\mathrm{LiFePO}_{4}$ active cathode material in lithium battery cell. A model composite system consisting of the CCL formed on fine grains of $\alpha-\mathrm{Al}_{2} \mathrm{O}_{3}$ was chosen. The $\alpha$-alumina is a well-defined inert support for the CCLs preparation and characterization because of its chemical and thermal stability and insulating behavior. The system was studied with thermal gravimetric analysis (TGA), Raman spectroscopy (RS), electrical conductivity (EC), specific surface area $\left(B E T-\mathrm{N}_{2}\right)$ measurements, and finally by transmission electron microscopy (TEM). Optimal composition of polymer carbon precursor was used to prepare $\mathrm{C} / \mathrm{LiFePO}_{4}$ cathode composites. 
Composites with $7 \mathrm{wt} \%$ of carbon were characterized using electrical conductivity measurements (EC) and transmission electron microscopy (TEM). The galvanostatic tests using CR 2032 cells were carried out to reveal electrochemical behavior of $\mathrm{C} / \mathrm{LiFePO}_{4}$ nanocomposite material.

\section{Material and Methods}

The idea of $\mathrm{C} / \alpha-\mathrm{Al}_{2} \mathrm{O}_{3}$ composite preparation is presented in Figure 1. Two methods of the composite precursors formation were applied.

In the first, the free radical precipitation polymerization of freshly distilled acrylonitrile (AN) was performed in the presence of $\alpha-\mathrm{Al}_{2} \mathrm{O}_{3}$ grains (POCh, Poland, 99.99\%, $\left.S_{\mathrm{BET}}=24 \mathrm{~m}^{2} \mathrm{~g}^{-1}\right)$. The procedure was described in our previous paper [10]. Briefly, $\mathrm{C} / \alpha-\mathrm{Al}_{2} \mathrm{O}_{3}$ grains were suspended in water solution of $\mathrm{AN}$ (7wt.\%) and the polymerization was initiated by $2,2^{\prime}$-azobis(isobutyramidine hydrochloride) (Aldrich), upon which the obtained $\mathrm{PAN} / \alpha-\mathrm{Al}_{2} \mathrm{O}_{3}$ samples were washed, filtered, and dried in the vacuum at $50^{\circ} \mathrm{C}$. In the second method, the $\alpha-\mathrm{Al}_{2} \mathrm{O}_{3}$ grains were impregnated with polymers in water solutions. The polymers used were poly-N-vinylformamide (PNVF) obtained by radical-free polymerization from N-vinylformamide (Aldrich) [11] and pyromellitic acid modified (5-10wt.\%) PNVF (MPNVF) [12]. To achieve the impregnation, $\alpha-\mathrm{Al}_{2} \mathrm{O}_{3}$ grains were suspended in the solutions of respective polymers in water (8-15 wt.\%). Suspensions were stirred continuously until the solvent evaporated and the viscosity of the solutions became high enough to avoid sedimentation. Then the samples were dried in an air drier at $90^{\circ} \mathrm{C}$ overnight. Mass ratios, at which the polymer precursors were combined with $\alpha-\mathrm{Al}_{2} \mathrm{O}_{3}$ in the above composite precursors preparation procedures, are compiled in Table 1.

To obtain $\mathrm{C} / \alpha-\mathrm{Al}_{2} \mathrm{O}_{3}$ composites, following the preparation, the $\mathrm{PAN} / \alpha-\mathrm{Al}_{2} \mathrm{O}_{3}, \mathrm{PNVF} / \alpha-\mathrm{Al}_{2} \mathrm{O}_{3}$, and $\mathrm{MPNVF} / \alpha-$ $\mathrm{Al}_{2} \mathrm{O}_{3}$ composite precursors were pyrolysed in a tube furnace under the flow of $99.999 \%$ argon $\left(5 \mathrm{dm}^{3} \mathrm{~h}^{-1}\right)$ at 550 and $600^{\circ} \mathrm{C}$ for $24 \mathrm{~h}$. Active carbon was placed in front of the samples to consume traces of oxygen and thus minimize losses in the carbon layers.

The obtained $\mathrm{C} / \alpha-\mathrm{Al}_{2} \mathrm{O}_{3}$ composites were deep black with foamed slag-like structure, the one prepared from the MPNVF precursor being special in that it looked glassy and lustrous like graphite.

$\mathrm{LiFePO}_{4}$ powder was produced using high temperature ceramic synthesis which is described in detail in [13]. $\mathrm{C} / \mathrm{LiFePO}_{4}$ composites were prepared from the PNVF and MPNVF precursor (with $5 \%$ content of pyromellitic acid) by wet polymer impregnation followed by controlled pyrolysis. $\mathrm{PNVF} / \mathrm{LiFePO}_{4}$ and $\mathrm{MPNVF} / \mathrm{LiFePO}_{4}$ were calcined in $600^{\circ} \mathrm{C}$ for $12 \mathrm{~h}$ under constant argon (99.9997\%) flow.

Carbon content in composites was determined by the temperature programmed oxidation (TPO) using TGA [12]. All the samples prepared were subjected to further analysis.

The Raman spectroscopy measurements were performed for model composites $\left(\mathrm{C} / \alpha-\mathrm{Al}_{2} \mathrm{O}_{3}\right)$ on thin pellets containing $10 \mathrm{mg}$ of the carbon sample and $200 \mathrm{mg}$ of $\mathrm{KBr}$. The carbon
TABLE 1: Mass ratios of polymer precursors to $\alpha-\mathrm{Al}_{2} \mathrm{O}_{3}$ applied in the composite precursors preparation and the carbon content in the resulting $\mathrm{C} / \alpha-\mathrm{Al}_{2} \mathrm{O}_{3}$ composites.

\begin{tabular}{lccc}
\hline $\begin{array}{l}\text { Polymer } \\
\text { precursor (PP) }\end{array}$ & $\begin{array}{c}\mathrm{PP} / \alpha-\mathrm{Al}_{2} \mathrm{O}_{3} \\
\text { ratio }\end{array}$ & $\begin{array}{c}\text { Carbon content in } \\
\mathrm{C} / \alpha-\mathrm{Al}_{2} \mathrm{O}_{3}, \mathrm{wt} \%\end{array}$ & $\begin{array}{c}\text { Carbonization } \\
\text { efficiency, wt } \%\end{array}$ \\
\hline \multirow{4}{*}{ PAN } & 0.4 & 1.6 & 4.0 \\
& 0.8 & 5.1 & 6.9 \\
& 1.2 & 10.3 & 9.6 \\
& 1.6 & 20.6 & 16.3 \\
PNVF & 2.0 & 37.2 & 29.6 \\
\hline & 1.0 & 6.6 & 7.0 \\
& 1.2 & 8.1 & 7.3 \\
& 1.4 & 9.6 & 7.5 \\
& 1.6 & 11.5 & 8.1 \\
& 2.4 & 25.3 & 14.1 \\
& 3.2 & 31.9 & 14.6 \\
& 4.8 & 47.7 & 14.7 \\
\hline \multirow{4}{*}{ MPNVF } & 0.2 & 2.0 & 11.7 \\
& 0.4 & 5.6 & 16.0 \\
& 0.6 & 9.7 & 18.2 \\
& 0.8 & 13.5 & 18.7 \\
& 1.1 & 17.4 & 18.6 \\
& 1.8 & 23.8 & 17.4 \\
& 3.3 & 40.0 & 20.0 \\
\hline
\end{tabular}

samples were prepared by pyrolysis under the same process conditions as those applied in composites preparation. Spectra were recorded at room temperature using a triple grating spectrometer (JobinYvon, T 64000) equipped with a liquid nitrogen cooled CCD detector (JobinYvon, Model CCD3000). The spectral resolution of $2 \mathrm{~cm}^{-1}$ was set. An excitation wavelength at $514.5 \mathrm{~nm}$ was provided by an Arion laser (Spectra-Physics, Model 2025). The laser power at the sample position was about $20 \mathrm{~mW}$. Raman scattered light was collected with a $135^{\circ}$ geometry, and 5000 scans were accumulated to ensure acceptable signal-to-noise ratio.

The electrical conductivity of the composites was measured using the 4-probe method at temperatures from the range between $-40^{\circ} \mathrm{C}$ and $+55^{\circ} \mathrm{C}$. Due to their high elasticity, the carbon coated composite powders failed to be prepared in the form of pellets by the standard procedure. Instead, the powders were placed in a glass tube and pressed by a screwpress between parallel gold disc electrodes $(\phi=5 \mathrm{~mm})$ till the measured resistance remained constant.

The specific surface area measurements of the composites were performed in Micrometrics ASAP 2010 using the BET isotherm method. For that about $500 \mathrm{mg}$ of each sample was degassed at $250-300^{\circ} \mathrm{C}$ for $8 \mathrm{~h}$ under a pressure of $0.26-$ $0.4 \mathrm{~Pa}$ and subjected to $\mathrm{N}_{2}$ sorption at $-195.8^{\circ} \mathrm{C}$. The pore size distribution was determined using the $\mathrm{BJH}$ method.

Transmission electron microscopy investigation was performed using TECNAI G F20 $(200 \mathrm{kV})$ coupled with an energy dispersive X-ray spectrometer (EDAX). In order to fully describe morphology of obtained composite grains, 


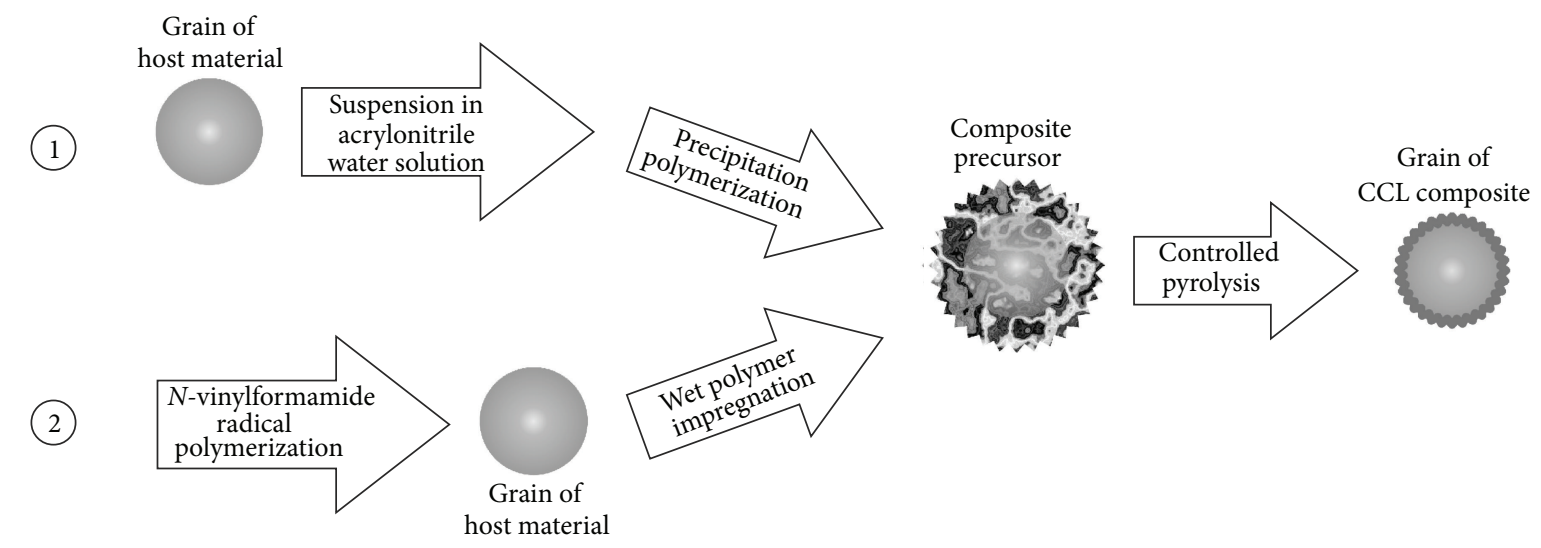

FIGURE 1: Schematic of the $\mathrm{C} / \alpha-\mathrm{Al}_{2} \mathrm{O}_{3}$ composite formation performed by polymer precipitation in suspension (1) or by polymer impregnation in water medium (2).

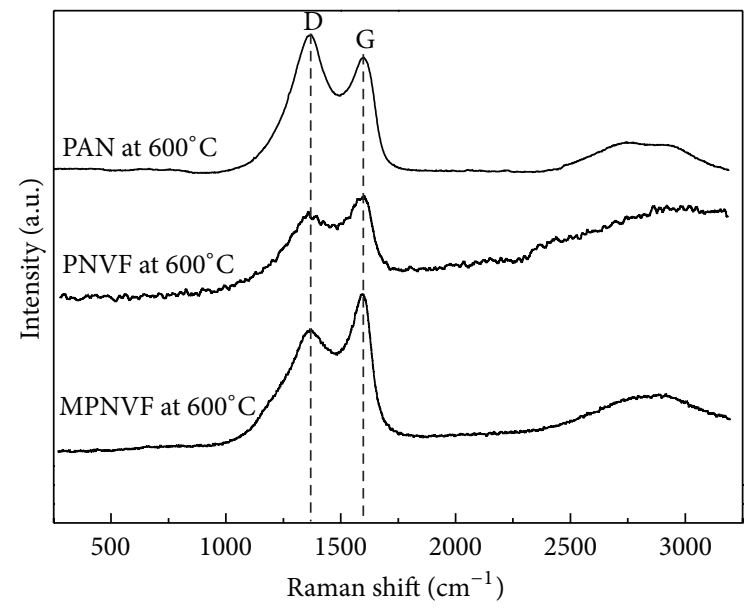

FIGURE 2: Raman spectra of the pyrolysed carbons derived from PAN, PNVF, and MPNVF precursors.

analysis was carried out in a bright field (BF) and high resolution (HREM) modes.

The charge-discharge cycling studies were conducted in two-electrode configuration using CR 2032 coin cell $\mathrm{Li} / \mathrm{Li}^{+} /\left(\mathrm{C} / \mathrm{LiFePO}_{4}\right)$ between 2.7 and $4.2 \mathrm{~V}$ at different $\mathrm{C}$ rates in room temperature conditions. $\mathrm{LiPF}_{6}(1 \mathrm{~mol})$ solution in EC/DEC (1:1) was used in cells as an electrolyte. All galvanostatic measurements were carried out using ATLAS 0961 MBI system.

\section{Results and Discussion}

The results of the Raman spectroscopy (RS) measurements are presented in Figure 2. The degree of carbon materials graphitization was characterized using the integral intensity ratio $D / G$, where the $D$ band (defect mode at about $1350 \mathrm{~cm}^{-1}$ ) corresponds to $s p^{3}$ diamond-like carbon structures and the $\mathrm{G}$ band (about $1600 \mathrm{~cm}^{-1}$ ) to $s p^{2}$ graphitic structures [14-17].
It was found that the graphitization degree increased with a decrease in the $\mathrm{D} / \mathrm{G}$ ratio. The lowest value of the $\mathrm{D} / \mathrm{G}$ ratio was observed for MPNVF precursor. This indicates the formation of the highest amounts of the graphite domains in the carbonized sample compared to the other precursors. Also, the G peak of the carbonized MPNVF precursor was downshifted and its width decreased, which suggests 2D ordering (1st phase of graphitization) [14-16]. Thus, the modification of PNVF by pyromellitic acid improves the polymer carbonization and the carbon layer formation. This may result from the fact that the planar structure of the PMA molecules serves as a nucleus of the graphite domains, which compete with the formation of the disordered structures. Likewise, for the same precursor the highest carbonization efficiency (the lowest loss of the carbon atoms from the precursor) was achieved (Table 1).

The results of the electrical conductivity measurements carried out on the $\mathrm{C} / \alpha-\mathrm{Al}_{2} \mathrm{O}_{3}$ samples are presented in Figure 3(a). As expected, the electrical conductivity of the composites increased with an increase in carbon loading. For the PNVF precursor, however, this increase was found much slower above $12 \mathrm{wt} . \%$ of C. Such an effect was not observed for the CCL obtained from the PAN and MPNVF precursors. By contrast, the activation energy of electrical conductivity remained nearly constant in the range of carbon content studied, suggesting a preservation of the conductivity mechanism of the CCL. Of the samples examined, the best electrical properties, that is, the highest conductivity and the lowest activation energy, were revealed by the composite based on the MPNVF precursor. Taking into account the results of the RS measurements, it may be concluded that the improvement of the electrical conductivity arose from the action of the pyromellitic acid modifier facilitating the achievement of the $2 \mathrm{D}$ ordered graphite structure. This way the desired value of the electrical conductivity of $10^{-2} \mathrm{~S} \mathrm{~cm}^{-1}$ was achieved. Simultaneously, the lowest activation energy (about $0.08 \mathrm{eV}$ ) of the electrical conductivity for these composite materials was observed.

The change in specific surface area with the carbon content on the $\mathrm{C} / \alpha-\mathrm{Al}_{2} \mathrm{O}_{3}$ composites is presented in Figure 3(b). 


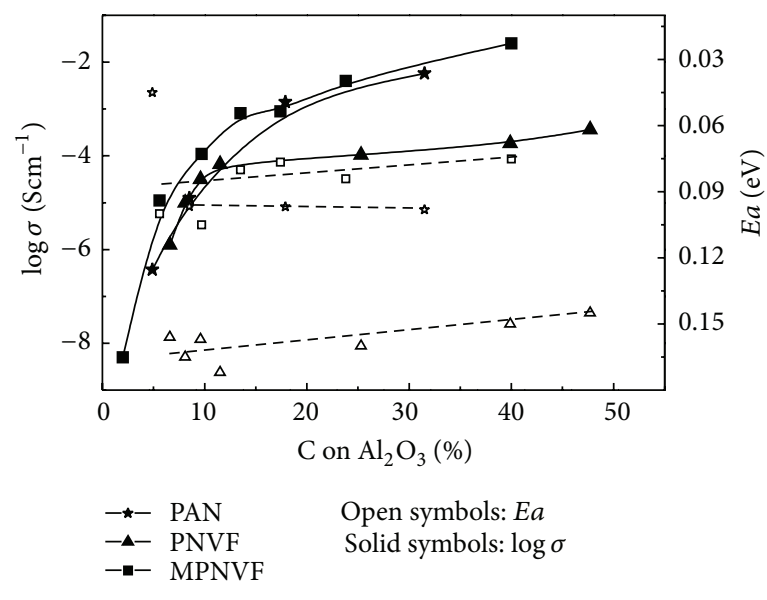

(a)

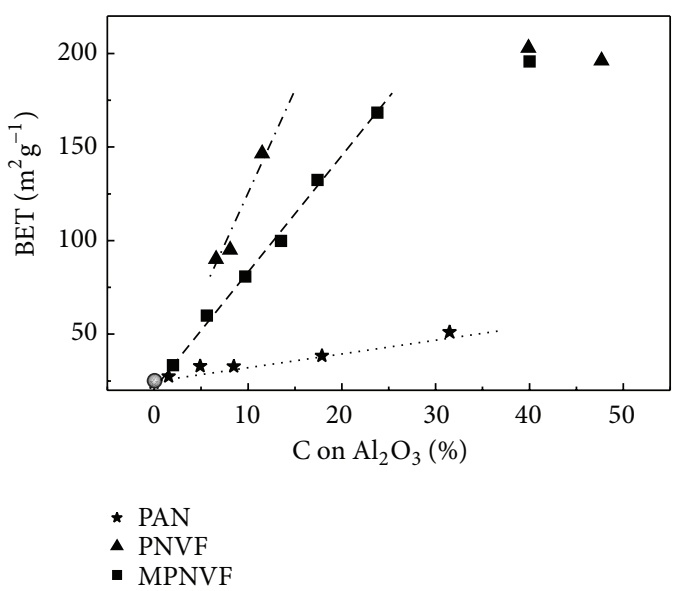

(b)

FIgURE 3: Electrical properties (a) and dependence of the specific surface area (b) of the $\mathrm{C} / \alpha-\mathrm{Al}_{2} \mathrm{O}_{3}$ composites on carbon content.

For all studied samples specific surface areas increased linearly with carbon loading up to $25-30 \mathrm{wt} . \%$, the rate of this increase being dependent on the polymer precursor. This suggests that the initial porous structure of the CCL was preserved regardless of the carbon content. Interestingly, for the PNVF precursor surface areas measured in the low carbon loading region were found much higher than those for MPNVF. This difference means that the modification of PNVF, with the PMA modifier resulting in MPNVF, brought about the formation of another type of CCL, where most probably the formed graphite domains are locally arranged in a manner that they limit the formation of disordered carbon.

The $\mathrm{N}_{2}$-adsorption-desorption isotherms and pore size distributions in the $\mathrm{C} / \alpha-\mathrm{Al}_{2} \mathrm{O}_{3}$ composites are presented in Figure 4 . The observed shapes of the isotherms (Figures 4(a)4(c)) correspond to the mixed I and IV types of isotherms (according to IUPAC nomenclature). Such shapes indicate the presence of micro- and mesopores within the CCL. The hysteresis loop of the H4 type (IUPAC) suggests the slotted pores located within the intergranular spaces. The textural properties of the composites on the other hand are generally similar, but there are differences in the pore size distribution (Figures 4(d)-4(f)). The smallest pores were found in the composite obtained from the PAN precursor. This fact can be related to the applied preparation method, that is, the precipitation polymerization resulting in filling of the pores by carbon particles. Unlike the PAN derived composite, the PNVF derived composite (Figures 4(b) and $4(\mathrm{e})$ ) revealed a highly porous structure with a relatively high number of micropores (about 30\%), this morphology being in agreement with the highest specific surface area (Figure 3(b)). By contrast, the composite derived from the MPNVF precursor showed a very uniform distribution of the mesopores with sizes within the range of $3-4.5 \mathrm{~nm}$ (Figure 4(f)). Also, the specific surface area of this composite that is lower by about $50 \%$ than that of the unmodified precursor (PNVF) (Figure 3(b)) suggests that a tighter carbon film with a lower content of the disordered carbon was formed in this sample.

Based on the electrical and morphological properties determined for the $\mathrm{C} / \alpha-\mathrm{Al}_{2} \mathrm{O}_{3}$ composites derived from the polymer precursors under investigation, the following structural model of these materials may be proposed (Figure 5). The CCL obtained from the PAN precursor (Figure 5(a)) consists of tightly packed small carbon particles, while that obtained from the PNVF precursor (Figure 5(b)) is built of carbon whiskers, this latter structure being reflected in a high specific surface area and a high share of micropores in this sample. This same PNVF precursor, when modified with pyromellitic acid (MPNVF precursor), strongly diminishes the specific surface area of the resulting composite, which is due to the formation of a tight, highly conductive carbon film with the defined porous structure that is dominated by mesopores with an arrow size distribution (Figure 5(c)).

The result, of the performed TEM studies on $\mathrm{C} / \alpha-\mathrm{Al}_{2} \mathrm{O}_{3}$ composites obtained from MPNVF precursor, is presented in Figures 6(a) and 6(b). A uniform dispersion of ceramic grains in an amorphous carbon matrix is observed in Figure 6(a). Moreover, Figure 6(b) revealed that obtained nanosized carbon coatings adhered closely to the ceramic support.

The $\mathrm{C} / \alpha-\mathrm{Al}_{2} \mathrm{O}_{3}$ composite morphology together with the electrical properties (Figure 3(a)) indicates that the MPNVF is an optimal polymer carbon precursor. Thus, the $\mathrm{C} / \mathrm{LiFePO}_{4}$ composite was prepared from MPNVF precursor with $5 \%$ of PMA with carbon content of $6 \mathrm{wt} . \%$.

TEM observations of $\mathrm{C} / \mathrm{LiFePO}_{4}$ obtained from MPNVF correspond to those of the model composites. Formed carbon coatings adhere well to the surface of active material grains; no voids can be visible at the $\mathrm{CCL} /$ material interface (Figures 6(c) and 6(d)). Figure 6(c) presents part of a single grain of $\mathrm{LiFePO}_{4}$ covered with conductive carbon layer with thickness of about $10 \mathrm{~nm}$. The high resolution electron microscopy micrograph (Figure 6(d)) shows a boundary between $\mathrm{LiFePO}_{4}$ grain and amorphous carbon layer. 


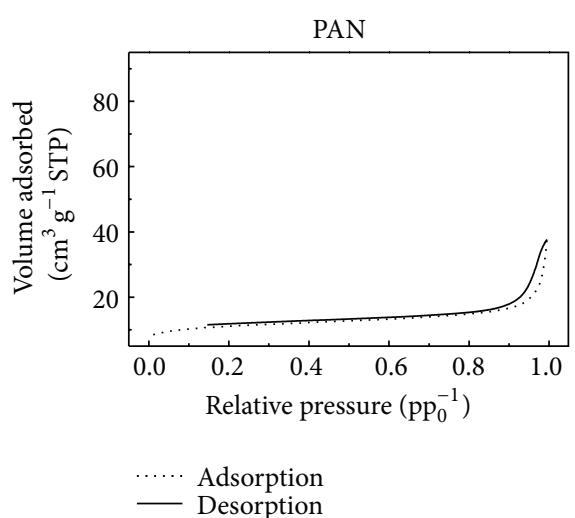

(a)

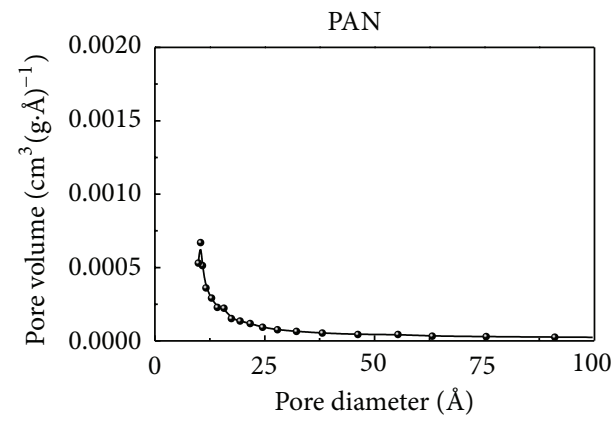

(d)

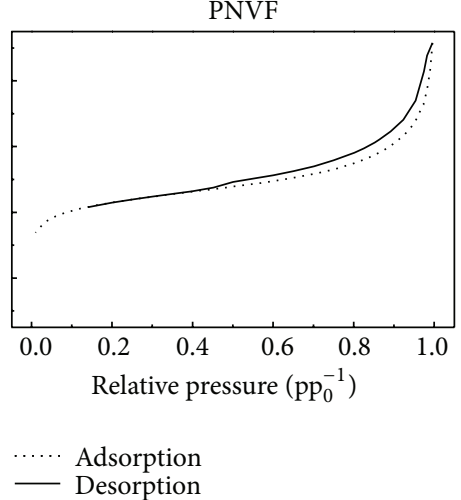

(b)

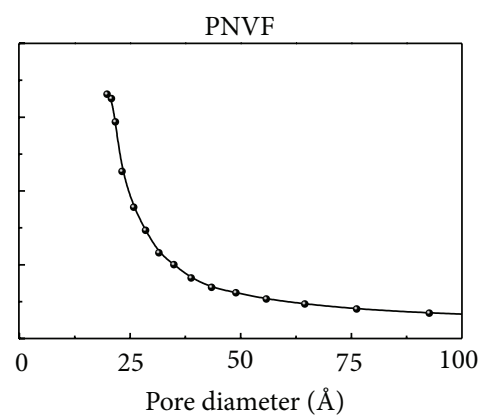

(e)

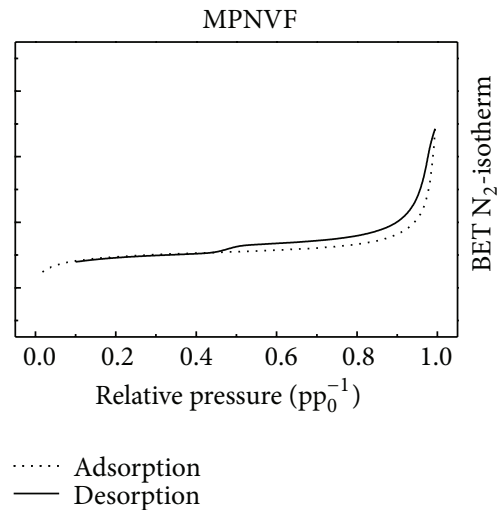

(c)

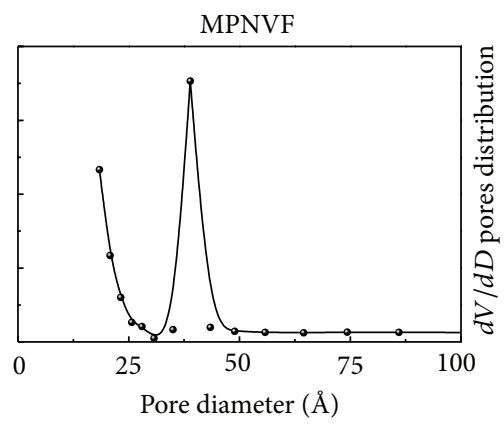

(f)

FIgure 4: Typical BET $\mathrm{N}_{2}$-isotherms of the $\mathrm{C} / \alpha-\mathrm{Al}_{2} \mathrm{O}_{3}$ composites.

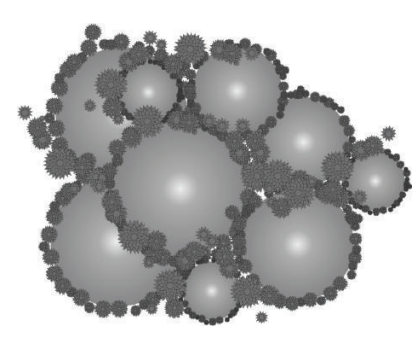

(a)

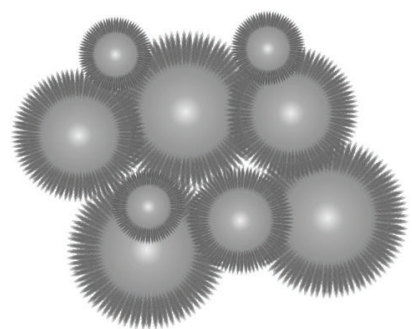

(b)

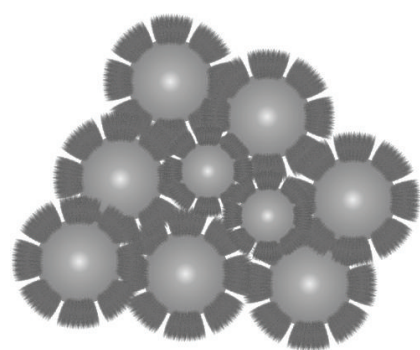

(c)

FIGURE 5: Model cross-section of the CCL composites derived from: PAN (a), PNVF (b), and MPNVF (c) precursors.

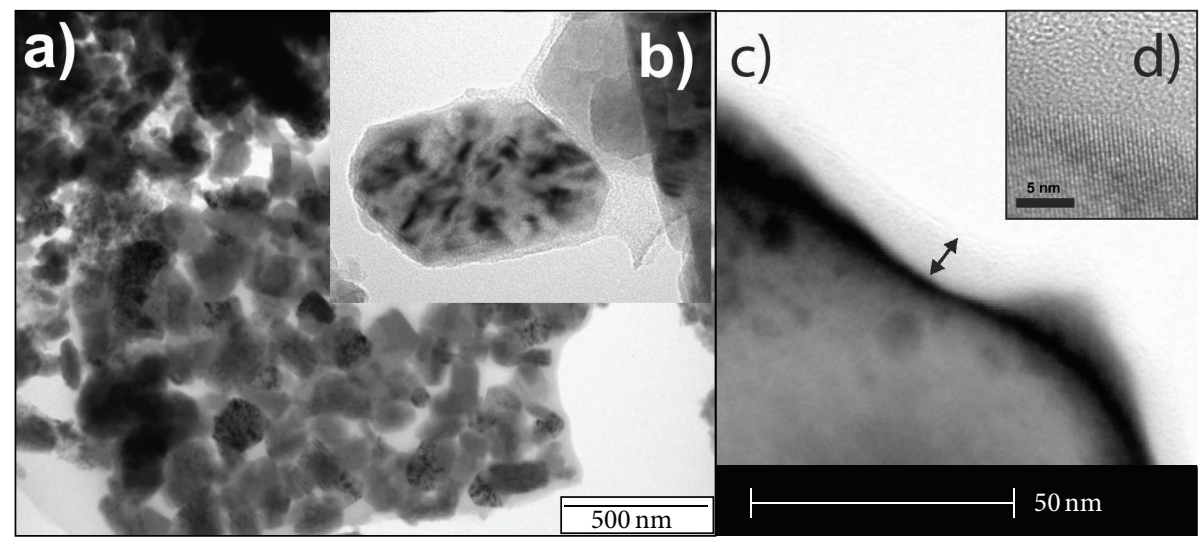

Figure 6: TEM micrographs of $\mathrm{C} / \mathrm{Al}_{2} \mathrm{O}_{3}$ and $\mathrm{C} / \mathrm{LiFePO}_{4}$ composites: (a) and (b) bright field micrographs of the $\mathrm{C} / \mathrm{Al}_{2} \mathrm{O}_{3}$ composite obtained from the MPNVF precursor, (c) bright field micrograph of a part of the $\mathrm{LiFePO}_{4}$ grain coated with amorphous carbon (marked with black arrow), and (d) high resolution micrograph of carbon/active material interface. 


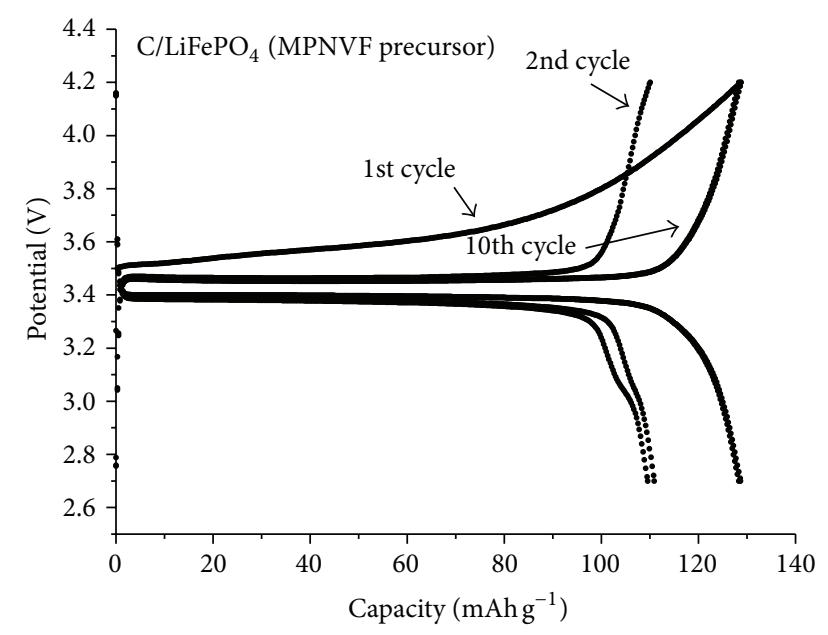

FIGURE 7: Charge/discharge voltage profiles (1st, 2nd, and 10th cycle) of $\mathrm{C} / \mathrm{LiFePO}_{4}$ composites obtained from MPNVF precursor.

Carbon coating improved electrical conductivity of $\mathrm{LiFePO}_{4}$ cathode material from $10^{-9} \mathrm{~S} \mathrm{~cm}^{-1}$ to the satisfactory level of $\sim 10^{-2} \mathrm{~S} \mathrm{~cm}^{-1}$. Electrical conductivity measurements of $\mathrm{C} / \mathrm{LiFePO}_{4}$ composites confirmed better performance of composites obtained from MPNVF carbon precursor (conductivity of $\mathrm{C} / \mathrm{LiFePO}_{4}$ obtained from MPNVF is c.a. one order of magnitude higher then conductivity of $\mathrm{C} / \mathrm{LiFePO}_{4}$ obtained from PNVF).

Charge-discharge cycling tests were carried out under $\mathrm{C} / 10$ rate. Figure 7 shows charge/discharge profiles of $\mathrm{C} / \mathrm{LiFePO}_{4}$ composites prepared form MPNVF. Curves for first, second, and tenth cycles are presented. From voltage profile shapes it can be seen that carbon layer undergoes activation during the first few cycles. Discharge capacity is c.a. $130 \mathrm{mAh} \mathrm{g}^{-1}$ after 10th cycle. Long term cycling stability tests show that composites with carbon coating prepared from PNVF precursor stopped working after 40 cycles and those with carbon prepared from MPNF were working stably with retained capacity after 100 cycles.

Complete structural and electrochemical analysis of $\mathrm{C} / \mathrm{LiFePO}_{4}$ composites obtained from different polymer precursors can be found in our previous work [17].

\section{Conclusions}

The electrical and morphological properties of the model $\mathrm{C} / \alpha-\mathrm{Al}_{2} \mathrm{O}_{3}$ composites showed a strong dependence on the nature of the polymer carbon precursors used to form carbon nanocoatings. This leads to the conclusion that the properties of CCL may be controlled by a proper composition of the polymer precursor. It was shown that the modification of poly-N-vinylformamide precursor with pyromellitic acid improved the electrical properties of the carbon coating and gave rise to the formation of the optimal pore structure. The proposed, water mediated, method of carbon coating of powdered supports, consisting of the use of polymer precursors, is capable of creating an appropriate mesoporous structure of the CCL which may assure easy pathways for ion transport (e.g., $\mathrm{Li}^{+}$). The method combines coating from solution and solid phase and is easily scalable. This feature may be used in preparation of carbon coated cathode materials composite for lithium-ion batteries. Moreover, these carbon films exhibit good electrical properties, which already fulfill the demand for low-conducting cathode materials (e.g., $\mathrm{LiFePO}_{4}$ ) to be applied in lithium-ion batteries. Also, due to its tightness, the CCL formed with use of the MPNVF precursor should be capable of improving chemical resistance of the cathode materials to the action of the electrolyte in the battery. On the other hand, the proposed method of $\mathrm{C} / \alpha-\mathrm{Al}_{2} \mathrm{O}_{3}$ composites formation, showing relatively high specific surface area and controlled porous structure of carbon layers, may be applied in preparation of novel composite adsorbents.

\section{Conflict of Interests}

The authors declare that there is no conflict of interests regarding the publication of this paper.

\section{Acknowledgments}

The authors acknowledge a financial support from the National Science Center of Poland under research Grant no. N N209 088638 and from the European Institute of Innovation and Technology, under the KIC InnoEnergy NewMat project. One of the authors (Michał Świętosławski) acknowledges a financial support from the International $\mathrm{PhD}$-studies programme at the Faculty of Chemistry, Jagiellonian University, within the Foundation for Polish Science MPD Programme. The part of the measurements was carried out with the equipment purchased thanks to the financial support of the European Regional Development Fund in the framework of the Polish Innovation Economy Operational Program (Contract no. POIG.02.01.00-12-023/08). TEM analysis was carried out in Laboratory of Transmission Analytical Electron Microscopyat the Institute of Metallurgy and Material Science, Polish Academy of Sciences.

\section{References}

[1] M. Armand and J.-M. Tarascon, "Building better batteries," Nature, vol. 451, no. 7179, pp. 652-657, 2008.

[2] B. Lin, Z. Wen, J. Han, and X. Wu, "Electrochemical properties of carbon-coated $\mathrm{Li}\left[\mathrm{Ni}_{1 / 3} \mathrm{Co}_{1 / 3} \mathrm{Mn}_{1 / 3}\right] \mathrm{O}_{2}$ cathode material for lithium-ion batteries," Solid State Ionics, vol. 179, no. 27-32, pp. 1750-1753, 2008.

[3] R. Guo, P. Shi, X. Cheng, and C. Du, "Synthesis and characterization of carbon-coated $\mathrm{LiNi}_{1 / 3} \mathrm{Co}_{1 / 3} \mathrm{Mn}_{1 / 3} \mathrm{O}_{2}$ cathode material prepared by polyvinyl alcohol pyrolysis route," Journal of Alloys and Compounds, vol. 473, pp. 53-59, 2009.

[4] B. L. Cushing and J. B. Goodenough, "Influence of carbon coating on the performance of a $\mathrm{LiMn}_{0.5} \mathrm{Ni}_{0.5} \mathrm{O}_{2}$ cathode," Solid State Sciences, vol. 4, no. 11-12, pp. 1487-1493, 2002.

[5] J. Hassoun, G. Derrien, S. Panero, and B. Scrosati, "The role of the morphology in the response of $\mathrm{Sb}-\mathrm{C}$ nanocomposite electrodes in lithium cells," Journal of Power Sources, vol. 183, no. 1, pp. 339-343, 2008. 
[6] J.-K. Kim, G. Cheruvally, J.-H. Ahn, and H.-J. Ahn, "Electrochemical properties of LiFePO4/C composite cathode material: carbon coating by the precursor method and direct addition," Journal of Physics and Chemistry of Solids, vol. 69, no. 5-6, pp. 1257-1260, 2008.

[7] J.-K. Kim, G. Cheruvally, and J.-H. Ahn, "Electrochemical properties of $\mathrm{LiFePO} 4 / \mathrm{C}$ synthesized by mechanical activation using sucrose as carbon source," Journal of Solid State Electrochemistry, vol. 12, no. 7-8, pp. 799-805, 2008.

[8] G. Ting-Kuo Fey, T.-L. Lu, F.-Y. Wu, and W.-H. Li, "Carboxylic acid-assisted solid-state synthesis of $\mathrm{LiFePO} 4 / \mathrm{C}$ composites and their electrochemical properties as cathode materials for lithium-ion batteries," Journal of Solid State Electrochemistry, vol. 12, no. 7-8, pp. 825-833, 2008.

[9] Y.-J. Choi, Y.-D. Chung, C.-Y. Baek, K.-W. Kim, H.-J. Ahn, and J.-H. Ahn, "Effects of carbon coating on the electrochemical properties of sulfur cathode for lithium/sulfur cell," Journal of Power Sources, vol. 184, no. 2, pp. 548-552, 2008.

[10] M. Molenda, R. Dziembaj, Z. Piwowarska, and M. Drozdek, "A new method of coating powdered supportswith conductive carbon films," Journal of Thermal Analysis and Calorimetry, vol. 88, no. 2, pp. 503-506, 2007.

[11] M. Molenda, R. Dziembaj, Z. Piwowarska, and M. Drozdek, "Electrochemical properties of $\mathrm{C} / \mathrm{LiMn}_{2} \mathrm{O}_{4-y} \mathrm{~S}_{y}(0 \leq \mathrm{y} \leq 0.1)$ composite cathode materials," Solid State Ionics, vol. 179, no. 1-6, pp. 88-92, 2008.

[12] M. Molenda, R. Dziembaj, A. Kochanowski, E. Bortel, M. Drozdek, and Z. Piwowarska, "Process for the preparation of conductive carbon layers on powdered supports," PAT. 216549; US Patent Application 20110151112.

[13] W. Ojczyk, J. Marzec, K. Świerczek et al., "Studies of selected synthesis procedures of the conducting $\mathrm{LiFePO}_{4}$-based composite cathode materials for Li-ion batteries," Journal of Power Sources, vol. 173, no. 2, pp. 700-706, 2007.

[14] A. C. Ferrari and J. Robertson, "Interpretation of Raman spectra of disordered and amorphous carbon," Physical Review B: Condensed Matter and Materials Physics, vol. 61, no. 20, pp. 14095-14107, 2000.

[15] C. Fauteux, R. Longtin, J. Pegna, and M. Boman, "Raman characterization of laser grown carbon microfibers as a function of experimental parameters," Thin Solid Films, vol. 453-454, pp. 606-610, 2004.

[16] S. Osswald, E. Flahaut, H. Ye, and Y. Gogotsi, "Elimination of D-band in Raman spectra of double-wall carbon nanotubes by oxidation," Chemical Physics Letters, vol. 402, no. 4-6, pp. 422427, 2005.

[17] M. Molenda, M. Swietoslawski, A. Milewska et al., "Carbon nanocoatings for $\mathrm{C} / \mathrm{LiFePO}_{4}$ composite cathode," Solid State Ionics, vol. 251, pp. 47-50, 2013. 

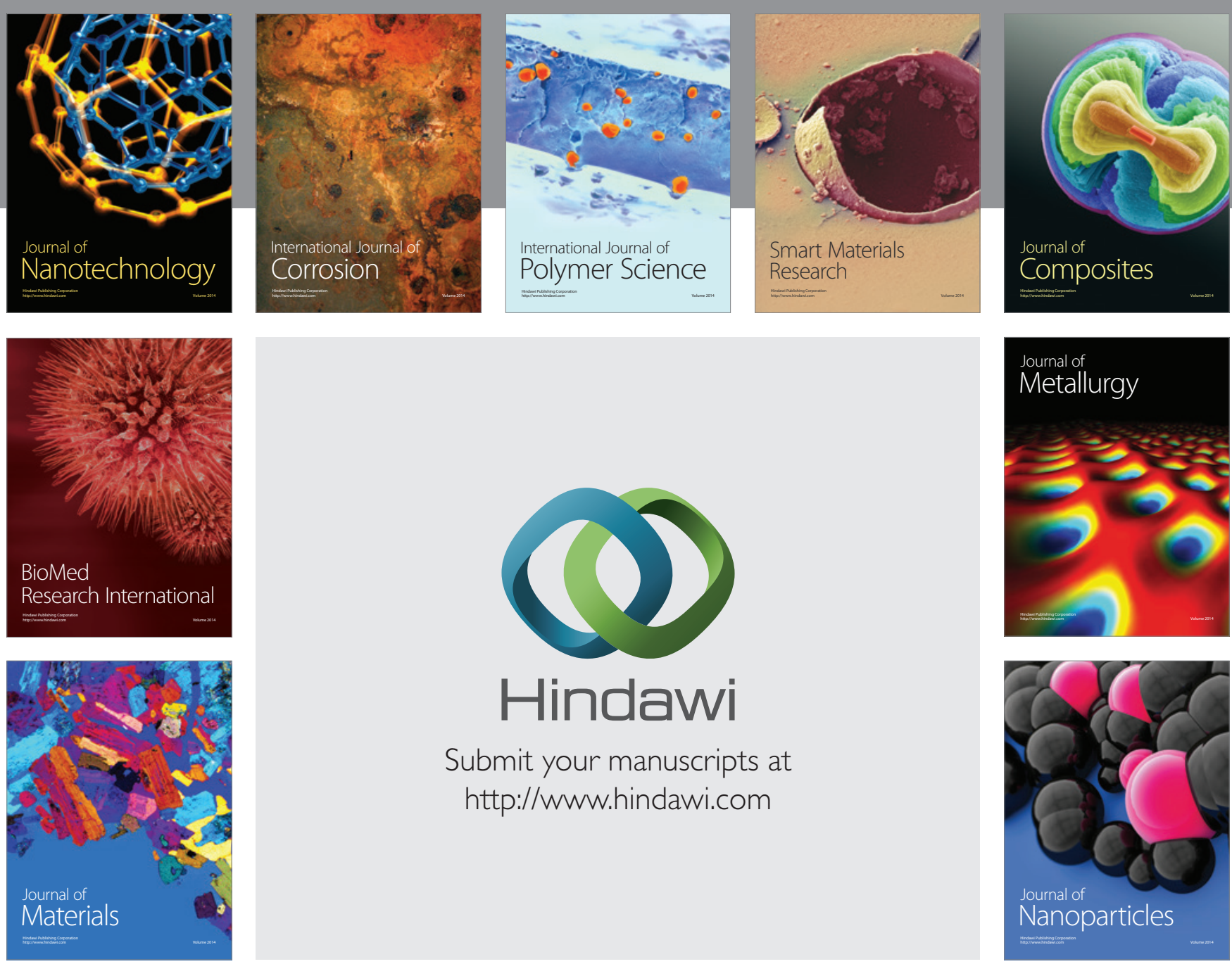

Submit your manuscripts at http://www.hindawi.com
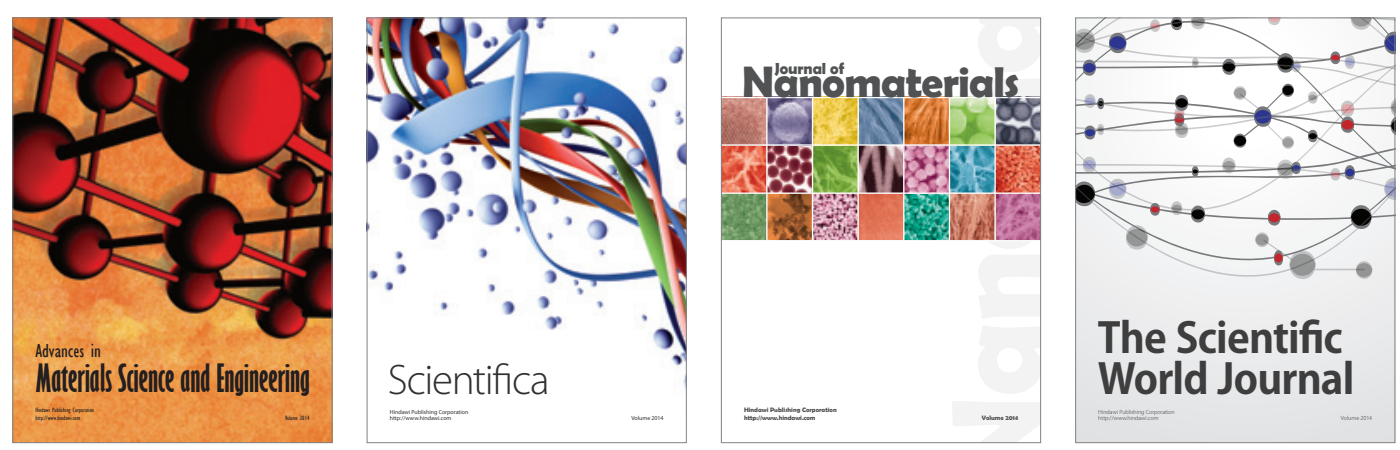

\section{The Scientific World Journal}
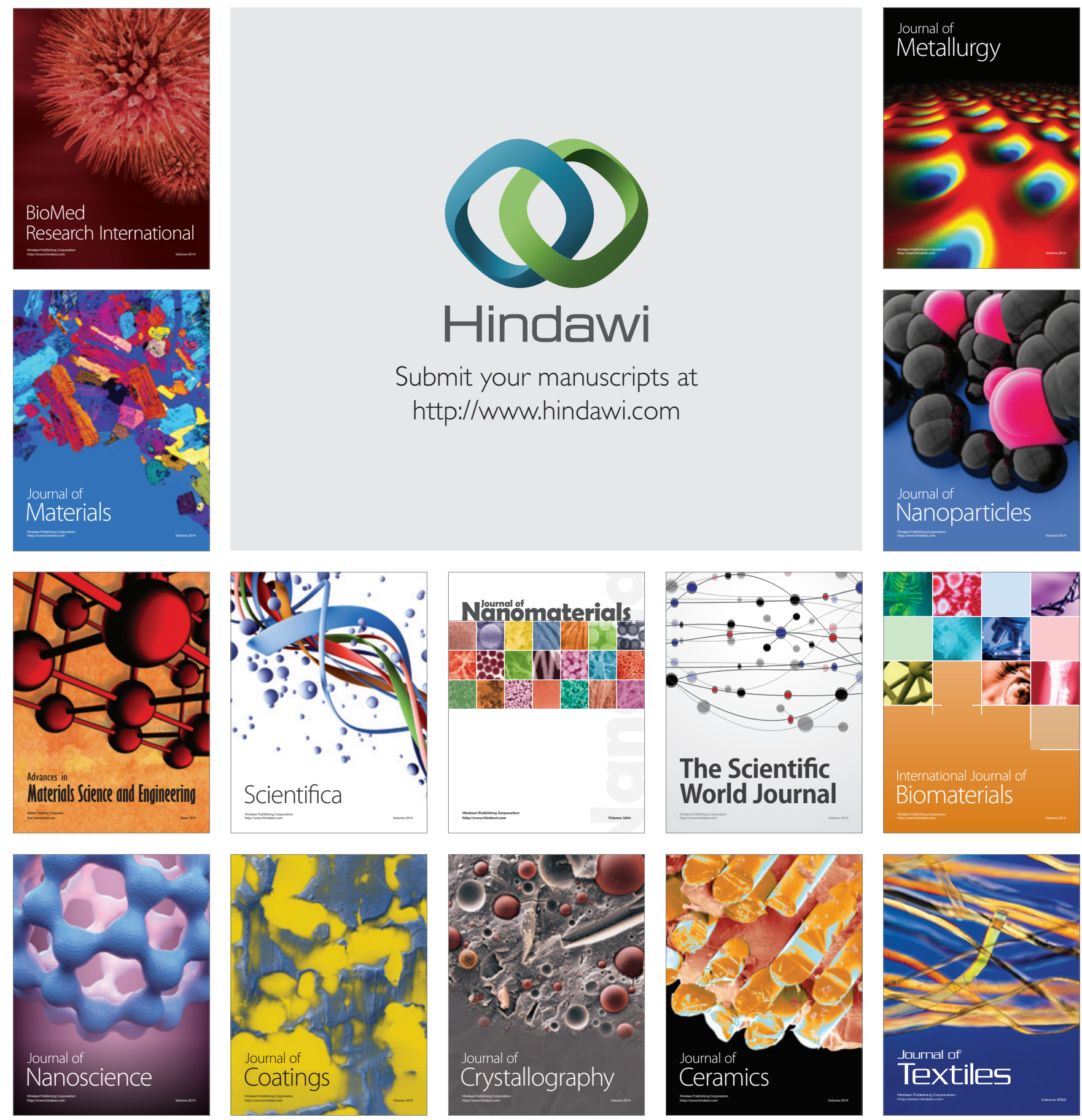